14 Lewis G, Pelosi AJDG. Measuring psychiatric disorder in the community: a standardised assessment for use by lay interviewers. Psychol Med 1992;22:465-86

15 Monck E, Graham P, Richman N, Dobbs R. Adolescent girls. II. Background factors in anxiety and depressive states. $\mathrm{Br} J$ Psychiatry 1994;165:770-80.

16 Henderson S, Duncan-Jones P, Byrne DG, Scott R. Measuring social relationships. The interview schedule for social interaction. Psychol Med 1980;10:723-34

17 Greenland S, Drescher K. Maximum likelihood estimation of the attributable fraction from logistic models. Biometrics 1993;49:865-72.

18 Craig WM. The relationship among bullying, victimisation, depression, anxiety, and aggression in elementary school children. Pers Indiv Diff 1998;24:123-30
19 Boulton MJ, Underwood K. Bully/victim problems among middle school children. BrJ Educ Psychol 1992;62:73-87.

20 Slee PT, Rigby K. Australian school children's self appraisal of interpersonal relations: the bullying experience. Child Psychiatry Hum Dev 1993;23:273-82.

21 Hodges EVE, Perry DG. Personal and interpersonal antecedents and consequences of victimisation by peers. J Pers Soc Psychol 1999:76:677-85.

22 Patton G, Hibbert M, Carlin JB, Shao Q, Rosier M, Caust J, et al. Menarche and onset of depression and anxiety in Victoria, Australia. J Epidemiol Community Health 1996;50:661-6.

23 Rothman KJ, Greenland S. Modern epidemiology. Philadelphia, PA: Lippincott-Raven, 1998.

(Accepted 21 May 2001)

\title{
Prescribing of drugs for use outside their licence in palliative care: survey of specialists in the United Kingdom
}

\author{
Hilary Pavis, Andrew Wilcock
}

Hayward House Macmillan Specialist Palliative Care Unit, Nottingham City Hospital NHS Trust, Nottingham NG5 1PB

Hilary Pavis specialist registrar in palliative medicine

continued over

BMJ 2001;323:484-5
A quarter of all prescriptions in palliative medicine are for licensed drugs that are used for unlicensed indications or that are given by an unlicensed route. Such prescriptions may affect two thirds of inpatients in specialist palliative care units. ${ }^{12}$ Doctors have been recommended to record in the patient's notes the reason for prescribing outside the licence; to explain, where possible, the position to the patient (and carers, if appropriate) in sufficient detail to allow informed consent to be given; and to inform other professionals involved in the care of the patient of such prescribing, so that misunderstandings are avoided. ${ }^{3}$ Given the widespread use of drugs outside their licence in palliative care, strict adherence to these recommendations

\begin{tabular}{|c|c|c|c|}
\hline $\begin{array}{l}\text { 1. Does your service operate a policy on providing information to } \\
\text { patients and their carers about the prescribing of } \\
\text { licensed drugs for unlicensed uses/routes? }\end{array}$ & \multicolumn{2}{|c|}{$\begin{array}{l}\text { Yes } \\
2(2)\end{array}$} & $\begin{array}{c}\text { No } \\
113(97)\end{array}$ \\
\hline \multicolumn{4}{|l|}{$\begin{array}{l}\text { If 'yes' please provide any details/documentation of any policy } \\
\text { your service is operating }\end{array}$} \\
\hline 2. Do you limit the prescribing of drugs in this way to consultants & \multicolumn{2}{|c|}{$20(17)$} & $93(79)$ \\
\hline 3. Do you obtain verbal consent from the patient/carers? & $\begin{array}{l}\text { Always } \\
5(4)\end{array}$ & $\begin{array}{c}\text { Sometimes } \\
62(53)\end{array}$ & $\begin{array}{c}\text { Never } \\
45(38)\end{array}$ \\
\hline 4. Do you obtain written informed consent from the patient/carers? & $0(0)$ & $4(3)$ & $109(93)$ \\
\hline $\begin{array}{l}\text { 5. Do you document in the notes when you are using drugs outside } \\
\text { of their licence and the reasons for this? }\end{array}$ & $6(5)$ & $48(41)$ & $58(50)$ \\
\hline 6. Do you inform other professionals when using such medication? & $7(3)$ & $80(68)$ & $25(21)$ \\
\hline $\begin{array}{l}\text { If you have answered 'always' to any of the above please provide } \\
\text { details/documentation of any policy your service is operating } \\
\text { If you have answered 'sometimes' to any of the above please } \\
\text { answer the following questions }\end{array}$ & & & \\
\hline $\begin{array}{l}\text { 7. How often have you obtained verbal or written informed consent } \\
\text { from patients/carers or documented in the notes the reasons for using } \\
\text { licensed drugs for unlicensed uses/routes in the past six months? }\end{array}$ & $\begin{array}{c}\text { No of ti } \\
0 \\
1-3 \\
4-6 \\
7-10 \\
>10\end{array}$ & $\begin{array}{l}1 \\
4 \\
1 \\
1\end{array}$ & $\begin{array}{c}16(20) \\
41(50) \\
14(17) \\
1(1) \\
10(12)\end{array}$ \\
\hline \multicolumn{4}{|l|}{ 8. Please list the particular drugs, their use and route of administration } \\
\hline $\begin{array}{l}\text { 9. Please add any comments that you may have about the obtaining } \\
\text { of informed consent from patients/carers and documenting the use of } \\
\text { licensed drugs for unlicensed purposes/routes in relation to your } \\
\text { palliative medicine practice }\end{array}$ & & & \\
\hline
\end{tabular}

Questionnaire on unlicensed use of drugs that was sent to palliative medicine specialists, with numbers (percentages) of responses $(n=117)$ to multiple choice questions may be impractical. In view of the implications of these recommendations for doctors in palliative medicine and other doctors they advise, a position statement endorsed by the specialty would be helpful. We undertook a survey of current practice to inform the debate.

\section{Participants, methods, and results}

All 182 palliative care services in the United Kingdom with a medical director or consultant were asked to complete anonymously a postal questionnaire in October 1999 (figure). Informed consent was defined thus: "Patients have been given the information they asked for or need about their treatment in a way they can understand so that whenever possible the patients have understood the nature, purpose and material risks of what is proposed and consent to it before you provide treatment."

One hundred and seventeen questionnaires (64\%) were returned. When unlicensed prescribing was limited to consultants, this was generally in the context of a consultant based service. No respondents always obtained written consent to unlicensed use, and only a minority $(<5 \%)$ always obtained verbal consent, documented unlicensed use in the patient's notes, or informed other professionals of it. The drugs for which these recommended practices were sometimes carried out were ketamine (58 reports), octreotide (19), ketorolac (15), midazolam (10), gabapentin (10), and amitriptylline (10). The only unlicensed drug use for which three of the services sometimes obtained written consent was gabapentin for neuropathic pain-an indication for which it became licensed in 2000 .

Invited comments covered three main themes. Firstly, respondents said that, given the prevalence of unlicensed use, it is impractical to obtain written consent routinely-and that discussion of unlicensed use could create unnecessary anxiety for the patient or carer. Secondly, some respondents sought consent only when prescribing drugs whose unlicensed use was not established in the specialty. Finally, other respondents made no distinction between licensed and unlicensed use and did not obtain verbal informed consent for use of any drug. 


\section{Comment}

When prescribing drugs for use outside their licence, most specialists in palliative medicine do not routinely obtain verbal or written informed consent, document the reason for unlicensed use in the patient's notes, or inform other involved professionals of unlicensed use. When they do obtain consent, it is likely to be for the use of less established drugs and to be verbal rather than written. Strict adherence to the recommendations is not welcomed by palliative care specialists because of the number of drugs involved and the burden to patients and carers.

This view is shared by the Royal College of Paediatrics and Child Health-the use of drugs outside their licence is also common in paediatrics-which has stated that in general it is not necessary to obtain the explicit consent of parents, carers, or patients for un- licensed use. The royal college has also stated that NHS trusts and health authorities should support therapeutic practices that are advocated by a respectable, responsible body of professionals. ${ }^{45}$

Contributors: AW conceived the survey. HP and AW collated and analysed the data and wrote the paper, and both will act as guarantors.

Competing interests: None declared.

Atkinson CV, Kirkham SR. Unlicensed uses for medication in a palliative care unit. Palliat Med 1999;13:145-52.

2 Todd J, Davies A. Use of unlicensed medication in palliative medicine Palliat Med 1999;13:446.

3 Cohen PJ. Off-label use of prescription drugs: legal, clinical and policy considerations. Eur J Anaesthesiol 1997;14:231-5.

4 Royal College of Paediatrics and Child Health. Medicines for children. London: RCPCH, 1999.

5 Conroy S, Choonara I, Impicciatore P, Mohn A, Arnell H, Rane A, et al Survey of unlicensed and off label drug use in paediatric wards in European countries. BMJ 2000;320:79-82.

(Accepted 14 May 2001)

\title{
Adverse events following acupuncture: prospective survey of 32000 consultations with doctors and physiotherapists
}

\author{
Adrian White, Simon Hayhoe, Anna Hart, Edzard Ernst
}

Acupuncture is increasingly popular, but it is not free from risk for the patient. ${ }^{1}$ Safety is best established with prospective surveys. Our aim was to ascertain the incidence of adverse events related to acupuncture treatment, as currently practised in Britain by doctors and physiotherapists.

\section{Participants, methods, and results}

Volunteer acupuncture practitioners were recruited through journals circulated to members of the British Medical Acupuncture Society and the Acupuncture Association of Chartered Physiotherapists (approximately 2750 members). ${ }^{2}$ A prospective survey was undertaken using forms for intensive event monitoring that had been piloted previously. ${ }^{3}$ Minor adverse events were defined as "any ill-effect, no matter how small, that is unintended and non-therapeutic, even if not unexpected." These events were reported every month, along with the total number of consultations. Minor or serious events that were considered to be "significant"-"unusual, novel, dangerous, significantly inconvenient, or requiring further information"-were reported on separate forms when they occurred. Anonymous reporting was accepted. A sample size of 30000 consultations was necessary to identify with $95 \%$ confidence any adverse event with a frequency of 1 in 10000 consultations. $^{4}$

Estimates of incidences per 10000 population were calculated with the acupuncturist (not the consultation) as the primary sampling unit. Since the data were skewed, with extreme values present, confidence intervals corrected for bias were calculated using bootstrapping procedure "bs" on estimates from the function "svyratio" in intercooled Stata version 6.0 with 10000 replications.
Data were collected from June 1998 to February 2000 from 78 acupuncturists, 13 of whom chose to remain anonymous. The average age of the acupuncturists was 47 (range 27-71) years, $61 \%$ were doctors and $39 \%$ physiotherapists, and $71 \%$ had practised for five years or more. In all, 31822 (median 318, range 5-1911) consultations were included.

Altogether, 43 "significant" events were reported (table), giving a rate of 14 per 10000 (95\% confidence interval 8/10 000 to 20/10 000). In addition, 48 apparently similar events were reported on the monthly forms, presumably due to different interpretations of "significant". All adverse events had cleared within one week, except for one incident of pain that lasted two weeks and one of sensory symptoms that lasted several weeks. According to accepted criteria, ${ }^{3}$ none $(0 / 10000$ to $1.2 / 10000$ ) of these events was serious.

A total of 2135 minor events was reported, giving an incidence of 671 per $10000(42 / 10000$ to $1013 /$ $10000)$ consultations. The most common events were bleeding (310 (160 to 590) per 10000 consultations) and needling pain (110 (49-247) per 10000 consultations). Aggravation of symptoms occurred in 96 (43-178) per 10000 consultations; in 70\% of these cases, there was a subsequent improvement in the presenting complaint. The highest rates reported by individual acupuncturists, expressed as a percentage of consultations, were 53\% for bleeding, 24\% for pain, and $11 \%$ for aggravation of symptoms.

\section{Comment}

Doctors and physiotherapists who performed acupuncture reported no serious adverse events and 671 minor adverse events per 10000 acupuncture consultations. These rates are classified as minimal ${ }^{5}$; however, 14 per 10000 of these minor events were reported as
University of Nottingham and Hayward House Macmillan Specialist Palliative Care Unit

Andrew Wilcock senior lecturer in palliative medicine and medical oncology Correspondence to: A Wilcock andrew.wilcock@ nottingham.ac.uk

See Editorial by Vincent and p 486

Department of Complementary Medicine, School of Postgraduate Medicine and Health Sciences, University of Exeter EX2 4NT

Adrian White senior lecturer Edzard Ernst professor Pain Clinic, Colchester District General Hospital,

Colchester CO4 5JL

Simon Hayhoe anaesthetist Faculty of Science, University of Central Lancashire, Preston PR1 2HE

Anna Hart

principal lecturer Correspondence to: A White

a.r.white@ex.ac.uk

BMJ 2001;323:485-6 